\title{
How Experimental Psychologists Write the Method Sections of Journal Articles
}

\author{
Weijen Zhuang ${ }^{1}$ \\ ${ }^{1}$ School of Management, Department of Applied Foreign Languages, Shih Chien University, Taipei, Taiwan \\ Correspondence: Weijen Zhuang, School of Management, Department of Applied Foreign Languages, Shih \\ Chien University, Taipei, Taiwan. E-mail: weichenchuan@g2.usc.edu.tw
}

Received: December 7, 2018 Accepted: December 30, 2018 Online Published: January 29, 2019

doi:10.5539/ijel.v9n2p15 URL: https://doi.org/10.5539/ijel.v9n2p15

\begin{abstract}
This paper reports an investigation on the move structures and cognitive genres found in the methods sections of research articles (RAs) in the field of experimental psychology. Thirty RAs of experimental psychology were analyzed in terms of the move structure and the cognitive genre applied to realize the moves. The analysis of the move structure of these research articles showed that the basic moves were: describing participants, describing data collection procedure(s) and explaining data analysis. The analysis of the cognitive genres used in the methods sections showed that authors typically require more than one cognitive genre to realize the major moves of the methods sections. The most commonly used cognitive genres in realizing the method section of a RA of experimental psychology were explanation and report. This suggests that the inclusion of the instruction of explanation and report in the EAP writing courses for the psychology major students is essential.
\end{abstract}

Keywords: methods sections, genre, move structures, cognitive genre, English for academic purposes

\section{Introduction}

For a graduate student, learning how to write academic articles is necessary in pursuing a career in the academic world. However, writing research article is the task that many students find it hard to accomplish. Analyzing the research articles composed by experienced skillful writers provide useful information for novice student writers learning to master the cognitive demanding task.

A research article (RA) is a genre used by the scholars to convince the readers, assumingly one's peers, that the knowledge claims proposed by the author are acceptable. The methods section of a RA plays a crucial rhetorical role in this persuasive speech of action. It describes the means through which the findings were obtained and validates them.

EAP researchers hold different opinions on the importance of the methods section of a RA. Some emphasized its importance while others downplayed its significance. Swales (1990) believed that the methods sections in science RAs are becoming de-emphasized and concise and may not deserve as much attention as the other sections. However, some scholars hold views on methods sections distinct from Swales'. Peacock (2011) mentioned that Swale's claim was based on the observation of a low number of RAs. In addition, Peacock cited Glenhill (2000) to question the assertion that the methods sections are less crucial. Gledhill examined 150 RAs on cancers and reported that the methods sections of these RAs constituted $32 \%$ of the total length of the texts, suggesting that the methods sections are not short and de-emphasized, at least in medical RAs on cancer. Moreover, Peacock (2011) found that the methods sections in RAs across eight disciplines including physics, biology, chemistry, environmental science, business, language and linguistics, law, and public and social administration constitute $25 \%$ of the total length of RAs, supporting the importance of the methods sections. Peacock is not alone on his stand on the significance of methods sections of RAs; Lim (2006) and Kanoksilapatham (2005) also called for the study of the generic structure of the methods sections in RAs, which they believed was under-researched. The fact that there are quite a few studies reporting on the move structure of the methods section in a RA in the past ten years also suggests that methods sections have continuingly being studied in the field of EAP (Swales \& Luebs, 2002; Kanoksilapatham, 2005; Lim, 2006; Lim, 2011; Peacock, 2011; Kanoksilapatham, 2015).

Most of the studies on methods sections focus on the rhetorical structure of the sections. Moves were the central 
concept used for analyzing the varied generic structure of the methods sections of many studies. Moves are a structural device of rhetoric through which the text is built systematically to aid communication in a staged or sequential manner. A move may contain several steps. According to Swales (1990), not all moves and steps are obligatory, and their sequence may vary; a move or a step can be repeated and may be embedded within each other (p. 58). Move analyses of the methods sections in various disciplines supported the claim that the generic structure of the methods section varies widely (Lim, 2006; Peacock, 2011; Kanoksilapatham, 2015). The findings of the previous studies revealed that the methods sections in science and engineering RAs share three basic moves: describing materials, describing procedure, and data analysis (Kanoksilapatham, 2007; Peacock, 2011; Kanoksilapatham, 2015). Although describing procedure and data analysis are also the most common moves in the methods sections of social sciences RAs, including those of language and linguistics, law, public and social administration, business, and management (Lim, 2006; Peacock, 2011), the methods sections in social sciences RAs tend to have more moves than those in most science and engineering RAs, except those of environmental sciences (Peacock, 2011). The additional moves in the methods sections of social sciences RAs were location, limitation, research aims/questions/hypotheses, and overview. This variation in moves in the methods sections of engineering and science RAs and the social sciences RAs confirm the disparity in the move structure in "hard" and "soft" sciences.

Although an academic writer requires the knowledge of the rhetorical structure of a genre to accomplish a writing task, the writer requires another type of compositional knowledge that is cognition oriented. This cognition-oriented knowledge enables a writer to compose various types of text in order to execute each move of a genre. Genre and text types may appear similar but are essentially different. Genre refers to a "message type" that is widely recognized in a specific discourse community, such as a business memo and a research article. Genre is largely a social phenomenon. By contrast, text types are cognition oriented and are described in categories, such as description, explanation, and recount (Knapp \& Watkins, 2005). A writer uses text types to realize a genre, such as complaint letters. A piece of written work, such as a research paper, is usually realized by multiple uses of various text types. Different terms have been developed to refer to genres and text types. For example, Pilegaard and Frandsen (1996) used text genres to refer to genres without developing another term for text types. Although the terms used vary, they share similar ideas. Furthermore, to master the skills of academic writing, students need both genre knowledge - knowledge of the recurrent content-organizing patterns of a genre - and text-type knowledge - the awareness of the major text types and the ability to compose texts of each text type (Paltridge, 2002; Bruce, 2005; 2008).

Bruce (2005) used "cognitive genres" to refer to text types. According to Bruce (2009), cognitive genres are "complex organizational categories that are usually drawn upon in combination when creating whole texts. They are described in terms of a model that draws upon cognitive, rather than social, or linguistic knowledge." (p. 107) On the basis of the four text types characterized by Biber (1989), Bruce proposed models for four cognitive genres that commonly occur in academic English prose. The models are listed in Table 1.

Table 1. Summary of the cognitive genre model

\begin{tabular}{|c|c|}
\hline \multicolumn{2}{|c|}{ Report: static descriptive presentation } \\
\hline Rhetorical focus & Presentation of data that is essentially not-sequential \\
\hline Gestalt structure & WHOLE PART structure of which PART has as UP DOWN structure \\
\hline Discourse pattern & Preview-details \\
\hline Interpropositional relations & $\begin{array}{l}\text { Amplification; reason-result, grounds-conclusion; simple contrast, simple comparison, concession-contra } \\
\text { expectation, condition-consequence }\end{array}$ \\
\hline \multicolumn{2}{|c|}{ Explanation: means-focused presentation } \\
\hline Rhetorical focus & The presentation of information with the orientation on means \\
\hline Gestalt structure & SOURCE PATH GOAL schema: LINK schema \\
\hline Discourse pattern & Preview-details \\
\hline Interpropositional relations & Means-purpose, means-result, amplification, concession-contra expectation \\
\hline \multicolumn{2}{|c|}{ Discussion: choice/outcome-focused presentation } \\
\hline Rhetorical focus & Focus on the organization of data in relation to (possible) outcomes/conclusions/choices \\
\hline Gestalt structure & CONTAINER schemata (more than one) \\
\hline Discourse pattern & Generalization-examples and matching \\
\hline Interpropositional relations & Grounds-conclusion, reason-result, means-purpose, means-result, concession-contra expectation \\
\hline \multicolumn{2}{|c|}{ Recount: sequential presentation } \\
\hline Rhetorical focus & Presentation of data or information that is essentially sequential or chronological \\
\hline Gestalt structure & SOURCE PATH GOAL schema \\
\hline Discourse pattern & General-particular, problem solution \\
\hline Interpropositional relations & Means-purpose, means-result, amplification, chronological sequence, grounds-conclusion, reason-result \\
\hline
\end{tabular}


Each model in the table has a rhetorical focus that relates to a general rhetorical goal, which targets a certain type of knowledge intended to be communicated. In addition, each model has an internal structure that includes three levels: gestalt structure, discourse pattern, and interpropositional relations.

Gestalt structures refer to the organization of the concepts or ideas in relation to the organization of the entire text. They are the "WHOLE-PART structure of which PART has an UP-DOWN structure." Discourse patterns refer to textual patterns, which tend to co-occur in a cognitive genre. Examples of discourse patterns are generalparticular, problem-solution, and preview-details. Interpropositional relations refer to the relation between two propositions: means-purpose and reason-result. Each cognitive genre is characterized by several interpropositional relations with high frequencies. As Bruce (2008) stated, interpropositional relations directly affect the linguistic selection related to cohesion and coherence.

Bruce developed models on the basis of the theories of cognitive science (2008). The models are hierarchical in nature because of the cognitive relations among the levels constituting them; the upper levels influence the lower levels. In other words, the rhetorical focus of a given text engages a specific gestalt structure, which leads to the engagement of specific discourse patterns and eventually affects the interpropositional relations within the text.

Bruce (2008) used cognitive genre structures for analyzing the methods sections in RAs and revealed that the methods sections of RAs of hard sciences and engineering (e.g., chemistry, pediatrics, and chemical engineering) tend to use a means-focused discourse structure, whereas those in RAs of soft sciences and social sciences (e.g., education, applied linguistics, and sociology) employ a combined chronological and nonsequential descriptive structure.

This study is concern with the move structure and the cognitive genre structures of methods sections of the journal articles in psychology. Psychology is often positioned in a gray, middle area in the academic spectrum with hard science on one extreme (e.g., physics) and soft sciences on the other (e.g., sociology). Bruce's study analyzed the cognitive genres independent of the rhetorical structures of the methods sections. However, each move or step has its communicative goal, which may require different combinations of cognitive genres to achieve the goals. Thus, an analysis of the cognitive genres used in each move of the move structure will provide comprehensive knowledge of the writing of methods sections.

In addition, Bruce (2008) studied the methods sections of the journal articles of the fields that are located near the two extremes and found a variance between the two groups in terms of the major cognitive genre structures in the methods sections. As the cognitive genres adopted by the researchers of the disciplines of the two extremes in writing the methods sections of RA are likely to vary, the preferred cognitive genres in the methods sections in the journal articles of a discipline in-between such as psychology requires scrutiny.

\section{Material and Methods}

\subsection{Corpus}

The corpus used in this study is a self-complied corpus of the methods sections of the leading journal articles of experimental and cognitive psychology.

Three professors were consulted to compile a list of leading journals of experimental psychology. The top journals in Scimago journal \& country rank were used as a guideline for journal selection. As a result, six journals were selected as the source from which the methods sections of the experimental RAs were selected: Annual Review of Psychology, Perspectives on Psychological Science, Psychological Inquiry, Psychological Review, Psychological Science, and Journal of Experimental Psychology: General.

Five articles of experimental psychology were randomly selected from each journal from the issues published between 2010 and 2016. Consequently, the corpus contained 30 texts with approximately 55,000 running words.

The English nativeness of the authors was not considered because the articles were published in leading journals and the writers were assumed to reach the required level of proficiency.

\subsection{Data Analysis}

The researcher together with the other coder, a research assistant who has a Master degree in TESOL, served as the coder of the study.

Five texts were randomly selected from the corpus to develop a coding prototype for the RAs. The primordial coding systems were then applied to the moves and steps coding of the rest of the texts, which was conducted independently by the author and the research assistant. Percentage agreement was computed to assess the inter-coder reliability. The results were summarized in Table 2: 
Table 2. Summary table of inter-coder reliability analysis of the moves and the steps

\begin{tabular}{lllll}
\hline Rhetorical Unit & Coded Unit & Agreement & Disagreement & Percent \\
\hline Moves & 92 & 84 & 8 & 91.30 \\
Steps & 297 & 246 & 51 & 82.82 \\
\hline
\end{tabular}

The results showed a high agreement on identifying the moves and the steps. Differences in the coding were discussed, negotiated and resolved.

Similar to Lim's study (2006), the two coders identified the boundaries of moves and steps with reference to markers such as typographical features and linguistic clues commonly used in the texts. However, it was unity of a segment that determined whether it was coded as a unit in the move analysis.

The cognitive genre model proposed by Bruce (2005) was adopted as the theoretical framework for the cognitive genre analysis. This model was considered appropriate for analyzing the text types of the RAs because the four cognitive genres identified by Bruce are commonly observed in academic English prose (Bruce, 2005; 2009; 2010).

All texts were coded independently by the author and the research assistant. The percentage agreement of the cognitive genre coding was calculated. The results were shown in Table 3.

Table 3. Summary table of inter-coder reliability analysis of the cognitive genres

\begin{tabular}{llll}
\hline Coded Unit & Agreement & Disagreement & Percent \\
\hline 202 & 194 & 8 & 96.03 \\
\hline
\end{tabular}

Note. $*$ The unit used for the identification of cognitive genres was paragraph.

The results showed that the cognitive genre of each paragraph in the texts was reliably identified by the two coders.

\section{Results}

\subsection{Move Structures of the Methods Sections}

The necessary moves in the methods sections were describing participants and describing data collection while those of corpus-based studies were describing the corpus and elucidating data analysis procedure(s). (Table 4).

Table 4. Moves and steps of the methods sections

\begin{tabular}{lll}
\hline Move/step & $\begin{array}{l}\text { Experimental } \\
\text { studies (N=30) }\end{array}$ & Percent \\
& Results & 100.00 \\
Move 1: Describing participants & $30 / 30$ & 100.00 \\
Detailing location, sample size and language-related features & $30 / 30$ & 60.00 \\
Specifying grouping procedure or grouping results & $18 / 30$ & 23.00 \\
Describing other participants & $7 / 30$ & 13.33 \\
Describing setting & $4 / 30$ & 6.67 \\
Recounting recruitment & $2 / 30$ & 40.00 \\
Move 2: Providing information about target features & $12 / 30$ & 30.00 \\
Describing target features & $9 / 30$ & 26.67 \\
Explaining the reasons for choosing this/these target feature(s) & $8 / 30$ & 3.33 \\
Explaining means to identify the target feature(s) & $1 / 30$ & 100.00 \\
Move 3: Describing data collection procedure(s) & $30 / 30$ & 53.33 \\
Presenting an overview of the design & $16 / 30$ & 100.00 \\
Describing materials/tasks used in the data collection process & $30 / 30$ & 70.00 \\
-Specifying instructional/experimental procedure(s) & $21 / 30$ & 43.33 \\
-Detailing materials/tasks/stimuli & $13 / 30$ & 53.33 \\
-Specifying administration of the tasks & $16 / 30$ & 43.33 \\
-Explaining development of the materials/tasks & $13 / 30$ & 13.33 \\
-Justifying the use of the materials/tasks & $4 / 30$ & 100.00 \\
Explaining method(s) measuring variables & $30 / 30$ & 56.67 \\
-Specifying items in questionnaires & $17 / 30$ & \\
\hline
\end{tabular}




\begin{tabular}{lll}
\hline -Specifying administration of the measurement & $20 / 30$ & 66.67 \\
-Detailing methods of scoring/rating/coding & $18 / 30$ & 60.00 \\
-Explaining development of the measurement & $5 / 30$ & 16.67 \\
-Justifying the measurement through citing previous studies & $4 / 30$ & 13.33 \\
-Justifying the measurement through providing information on reliability and & $10 / 30$ & 33.33 \\
validity & & 66.67 \\
Move 4: Elucidating data analysis procedure(s) & $20 / 30$ & 66.67 \\
Explaining statistical analysis & $20 / 30$ \\
The steps begin with a "-" are "sub-steps" of a step, which share the common communicative goals of this step at the upper \\
\end{tabular}
Note. *The steps begin with a "-" are "sub-steps" of a step, which share the common communicative goals of this step at the upper
conceptual level.

\subsection{Basic Moves and Major Steps in the Methods Sections of Experimental RAs}

The rhetorical structural units identified in the move analysis were classified into basic and optional ones based on the frequencies of occurrence. Those that were common to all Methods Sections in the study were labeled as basic units; those that appeared in some Methods Sections were labeled as optional units. In this study, total three moves were identified and they were all basic moves. That is, they appeared in all Methods Sections examined in the study. They were: describing participants, describing data collection procedure(s) and Explaining data analysis.

It is not surprising that describing participants, describing data collection procedure(s) and explaining data analysis were the three basic moves of Methods Sections. The goal of an experiment is to test a cause-effect relationship in an experimental design. The basic logic of an experimental design is to arrange the participants receiving two different treatments through which data relevant to the research questions are obtained in order to test the hypothetical cause-effect relationship between the treatment and the desired effect(s). Thus, data collection is a mandatory move in the methods sections of experimental RAs through which an author describes the data collection methodology to convince the readers that the data collected for analysis are appropriate and accurate.

The first move, describing participants had two basic steps and one optional step. The basic steps of the move were detailing location and sample size and recounting recruitment. The step of detailing location and sample size specifies the location where the participants received the treatments and the sample size of the experiment. The other basic step of this move, recounting recruitment, explains the recruiting procedure. Specifying grouping procedure or grouping results is an optional step but almost seventy percent of the methods sections examined contained this step, which suggests its importance.

The second move namely describing data collection procedure(s) may contain two major steps: Specifying experimental procedure(s) and explaining method(s) measuring variables. Specifying experimental procedure(s) details the experimental process and is a basic step of the move. Explaining method(s) measuring variables is also basic. It provides the information of the measurements of the experiment. Two sub-steps were identified in the study under the label of explaining method(s) measuring variables: specifying the administration of the measurements and specifying the items in questionnaires. Almost all of the methods sections examined contained the sub-step of specifying the administration of the measurements explaining how the measurements were conducted. By contrast, relatively few cases of specifying the items in questionnaires were found. The methods sections that contained specifying the items in questionnaires were in the research in which newly developed or self-developed measurement tools were adopted.

The last move, explaining data analysis, lists the statistical analysis planned to be used in data analysis. The textual length of this move tends to be brief and the clausal constructions are highly patterned across samples.

\subsection{Cognitive Genres Employed in the Methods Sections}

The cognitive genre that occurred most frequently in the methods sections of was explanation, followed by report. In the corpus, 115 of 202 paragraphs in the major steps in the basic moves were identified as explanation and 68 as report. In other words, 57\% were explanation and 34\% were report. Only 19 paragraphs (9\%) were identified as recount. Table 3 is a cross-reference table that summarizes the analysis of the cognitive genres of the basic moves and essential steps in the studied experimental RAs. 
Table 5. Cognitive genres in the methods sections

\begin{tabular}{ll}
\hline Moves/Steps & Number of paragraphs identified as a cognitive genre \\
\hline Move 1: Describing participants & \\
$\begin{array}{l}\text { Detailing location, sample size, and language-related features } \\
\text { Specifying grouping process or grouping results }\end{array}$ & Rp: 30 \\
Move 3: Describing data collection procedure(s) & Exp: 15 : 5 \\
Presenting an overview of the design & Exp: $12 ;$ Rp: $3 ;$ Rec: 1 \\
Describing materials/tasks used in the data collection process & Exp: $35 ;$ Rec: $15 ;$ Rp: 13 \\
Explaining measurement & Exp: $35 ;$ Rp: $17 ;$ Rec: 3 \\
Move 4: Elucidating data analysis (Note 1) & Exp: 20 \\
\hline
\end{tabular}

In addition, the analysis showed that the cognitive genres employed to realize a move or a step correlated with the communicative goals of the move or the step. For instance, the goal of the step location, sample size, and language features in the move participants was to provide the relevant features of the sample to support the appropriateness of the sample. The adoption of report is required to accomplish such a task. Conversely, the step the administration of the task in the move data collection describes the manner in which the task was conducted. Therefore, the cognitive genres that the writers required to accomplish this task were explanation and recount.

Because the cognitive genres employed to realize a step should enable the accomplishment of its communicative goals, the cognitive genres observed in one step are able to organize information of similar nature in various forms. For instance, explanation and recount were both found to occur frequently in the step instructional/ experimental procedure in the move data collection. Although explanation emphasizes the means-focused presentation and recount emphasizes the sequential presentation, both are able to organize chronological information, and these two cognitive genres are reasonable choices for a writer working on administration of the task.

Some cognitive genres constituting one step did not share similarities in organizing information. The step of grouping in the move participants was realized either by explanation or report. Most writers chose explanation to write the step grouping in the move participants, and few writers used report. The variance was caused by the different focus of the writers for reporting grouping. The writers who used explanation to realize the step focused on the process and the means of grouping, whereas writers that employed report focused on the results of the grouping. As the organization of the information of a grouping process is different from that of its results, the writers used different cognitive genres to realize the varied communicative goals found in a step.

Because the choice of the cognitive genre reflects the communicative goals of the moves and steps, the much higher amount of explanation than report and recount indicated that the most essential communicative goal of the methods sections is to explain the methodological means adopted by scientists to achieve certain objectives.

\section{Discussion}

The results of the analysis of the cognitive genres of the methods sections showed that it is nearly impossible to complete a methods section by using only one cognitive genre. The most frequently observed genre in the study was explanation, followed by report and recount. The added proportions of explanation and report and the paragraphs composed as a combination of these two equaled or even exceeded $90 \%$ of the total paragraphs in either the methods sections of the journal articles studied. These findings are not consistent with those reported by Bruce (2008), who reported that the methods sections of most RAs consisted of one cognitive genre and that the major cognitive genre in the methods sections of social sciences and physical sciences RAs were recount and explanation, respectively. By contrast, the results of the current study indicated that most writers of psychology did not complete the methods sections by using only one cognitive genre and that the most frequently identified cognitive genre in experimental and cognitive psychology journal papers was not recount. Explanation (followed by report) was the major cognitive genre in the methods sections of the reviewed RAs. The findings of the current study showed that the cognitive genres used by experimental and cognitive psychologists to complete the methods sections of their RAs were similar to those used by physical science scientists to complete the methods sections of their journal papers.

The findings of the study showed that writer usually needs more than one cognitive genre to write the methods sections. The findings of the study also suggest that because the major cognitive genres with high frequencies in the methods sections were explanation and report, mastering the writing skills of the two cognitive genres should be the focus of EAP teachers teaching academic writing to graduate students of experimental psychology. Furthermore, the findings of the study showed a similarity between the major cognitive genres in the methods 
sections adopted by writers of the journal articles of experimental psychology and those of physics. This suggests that the methodology adopted by psychology may share resemblances with that of the "hard" science because the writers of the methods sections of the journal papers of psychology tend to inactivate cognitive organizing categories similar to those of the hard science writers' in describing their research designs.

The findings of the study yield several pedagogical implications. First, the inclusion of the instruction of explanation and report in the EAP writing courses for the psychology major students is essential. However, this does not imply that the instruction of the other cognitive genres is not necessary. The cognitive genre of Discussion Sections, for example, can be reasonably expected to require the cognitive genre of Discussion. Second, the finding of the study indicating similarities between the cognitive organizing categories inactivated by the psychologists and the scientists of hard science in writing the Methods Sections suggests that EAP teachers may group the graduate students of the two majors in one discussion group because they may be able to support each other efficiently because the similar common grounds they share in methodology.

\section{Conclusion}

Cognitive genres realize the moves of an academic prose. A skillful academic writer needs both the knowledge of the rhetorical structure of the academic genre that one is working on and the ability to master the cognitive genres to achieve the communicative goals of each move. Therefore, EAP writing courses for graduate students should contain the instruction on both.

Also, previous studies have pointed out that the rhetorical structures of research article vary across disciplines. Because the rhetorical structures of research articles of different disciplines vary, the required cognitive genres to realize them vary accordingly. It would be inappropriate for EAP teachers teaching graduate students writing to provide identical writing training to students of different majors. Thus, more studies on how experienced research paper writers of different fields mapping the cognitive genres onto the move structure are important in providing relevant information to EAP teachers teaching students with different academic backgrounds.

\section{References}

Biber, D. (1989). A typology of English texts. Linguistics, 27, 3-43. https://doi.org/10.1515/ling.1989.27.1.3

Bruce, I. J. (2005). Syllabus design for general EAP courses: A cognitive approach. Journal of English for Academic Purposes, 4(3), 239-256. https://doi.org/10.1016/j.jeap.2005.03.001

Bruce, I. J. (2008). Cognitive genre structures in methods sections of research articles: a corpus study. Journal of English for Academic Purposes, 7(1), 38-54. https://doi.org/10.1016/j.jeap.2007.12.001

Bruce, I. J. (2009). Results sections in sociology and organic chemistry articles: A genre analysis. English for Specific Purposes, 28(2), 105-124. https://doi.org/10.1016/j.esp.2008.12.005

Collin-Kies, S. (2014). Methods reported in ESP research articles: A comparative survey of two leading journals. English for Specific Purposes, 36, 27-34. https://doi.org/10.1016/j.esp.2014.04.001

Egbert, J. (2007). Quality analysis of journals in TESOL and applied linguistics. TESOL Quarterly, 41(1), 157171. https://doi.org/10.1002/j.1545-7249.2007.tb00044.x

Fincher, K. M., \& Tetlock, P. E. (2016). Perceptual dehumanization of faces is activated by norm violations and facilitates norm enforcement. Journal of Experimental Psychology: General, 145(2), 131-146. https://doi.org/10.1037/xge0000132

Glenhill, C. (2000). The discourse function of collocation in research article introductions. English for Specific Purposes, 19(2), 115-135. https://doi.org/10.1016/S0889-4906(98)00015-5

Kanoksilapatham, B. (2005). Rhetorical structure of biochemistry research articles. English for Specific Purposes, 24(3), 263-292. https://doi.org/10.1016/j.esp.2004.08.003

Kanoksilapatham, B. (2007). Rhetorical moves in biochemistry research articles. In D. Biber \& U. Connor (Eds.), Discourse on the move: Using corpus analysis to describe discourse structure (pp. 73-119). Amsterdam/Philadelphia: John Benjamins Publishing Company. https://doi.org/10.1075/scl.28.06kan

Kanoksilapatham, B. (2015). Distinguishing textual features characterizing structural variation in research articles across three engineering sub-discipline corpora. English for Specific Purposes, 37, 74-86. https://doi.org/10.1016/j.esp.2014.06.008

Knapp, P., \& Watkins, M. (2005). Genre, text, grammar: Technologies for teaching and assessing writing. Sydney: UNSW Press. 
Lim, J. M. H. (2006). Method sections of management research articles: A pedagogically motivated qualitative study. English for Specific Purposes, 25(3), 282-309. https://doi.org/10.1016/j.esp.2005.07.001

Paltridge, B. (2002). Thesis and dissertation writing: An examination of published advice and actual practice. English for Specific Purposes, 21(2), 125-143. https://doi.org/10.1016/S0889-4906(00)00025-9

Peacock, M. (2011). The structure of the method section in research articles across eight disciplines. The Asian ESP Journal, 7(2), 97-123.

Pilegaard, M., \& Frandsen, F. (1996). Text type. In J. Verschueren, J. O. Ostaman, J. Blommaert \& C. C. Bulcaen (Eds.), Handbook of pragmatics (pp. 1-13). Amsterdam: John Benjamins Publishing Company.

Swales, J., \& Luebs, M. (2002). Genre analysis and the advanced second language writer. In E. Barton \& G. Stygall (Eds.), Genre in the classroom: multiple perspectives (pp. 105-119). Mahwah, NJ: Lawrence Erlbaum.

Swales, J. (1990). Genre Analysis: English for Academic and Research Settings. Cambridge: CUP.

\section{Note}

Note 1. The unit used for the identifying cognitive genres was paragraph. A paragraph can be identified as a complete unit of a cognitive genre, or a part of a unit of it; a paragraph can also contain two or more units of various cognitive genres. The move data analysis, not always present in the methods sections in the reviewed texts, is presented in the table because it is essential for experimental RAs. If it is not included in the methods sections, it must be present in the results sections.

\section{Appendix A}

\section{An Example of the Method Section of a Research Journal of Experimental Psychology Method}

Participants. Participants were 48 (28 men and 20 women) students at a northeastern university who participated in partial fulfillment of a course requirement. Data were collected over a 2-week period. Sample size was determined by the number of students who volunteered to participate in the 12 days between the study posting and the end of the term. The average age of participation was $20.4(\mathrm{SD}=.9)$ and average political ideology leaned liberal ( $\mathrm{M}=5.2$ on a 7 -point scale).

Stimuli. Seventy-two face stimuli were taken from Ballew and Todorov (2007). Our images were restricted to White make runner-ups in gubernatorial elections. Images were cropped to $150 * 215$ pixels, placed on a standard background, and converted to grayscale.

Procedure. We used a recognition memory task to measure perceptual dehumanization. For every participant, the experiment consisted of six blocks, each consisting of 12 face-action associations. As Figure 2 shows, each block consisted of a study phase and a test phase. In three blocks, faces appeared upright during both the study and test phases; in three blocks, the faces appeared as inverted during both the study and test phases.

In the study phase, participants learned 12 face-action pairings by simultaneously seeing a single face (either upright or inverted) and a single action on a screen for $8.5 \mathrm{~s}$. Participants were told the individual in the photograph had performed the action described below the photograph. During the test phase, actions appeared serially below the face array, and the participant identified the face originally linked to the action in the learning phase from the array. Participants were asked to identify the correct face from the array by indicating the number associated with the face. Face arrays were created by randomly assigning each of the 12 faces a number.

Actions systematically varied in moral valence. Negative actions, norm violations, were restricted to actions punishable by five or more years in prison according to mandatory minimum sentencing guidelines. Whenever, possible, the greater salience of negative things (Rozin \& Royzman, 2001), we defined positive actions as intentional actions that resulted in 2 to 3 times the positive impact as the negative actions caused harm. For example, a negative action of stealing $\$ 10,000$ dollars would be paired with a positive action of donating $\$ 30,000$, or murdering one individual was paired with saving the lives of two individuals. Neutral actions were defined as actions that had no obvious impact on others. For example, "wore a blue shirt to dinner."

To control for difficulty or learning effects, the order of blocks was randomized across participants. Faces and actions were randomly assigned to one of six blocks. For each participant, the order of faces was randomly determined within each block. When any specific face appeared, the action associated with the face was randomly determined. Actions were shown in a random order below an array consisting of all 12 faces. This 
structure of randomization allowed us to control for three potential biases: (a) order effects; (b) bias because of a specific face; (c) bias because of a face-action pairing.

After completing the memory task, participants were asked their sex, age and political beliefs. All measures and conditions are reported here.

(drawn from Fincher \& Tetlock, 2016, pp. 134-135).

\section{Copyrights}

Copyright for this article is retained by the author, with first publication rights granted to the journal.

This is an open-access article distributed under the terms and conditions of the Creative Commons Attribution license (http://creativecommons.org/licenses/by/4.0/). 